\title{
Pervious Concrete: Mix Design, Properties and Applications
}

\author{
Mohammed Sonebi ${ }^{a^{*}}$, Mohamed Bassuoni $^{b}$, Ammar Yahia $^{c}$

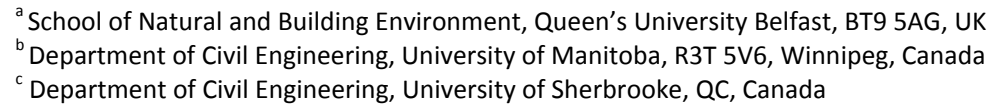

Received: 15 December 2016 / Accepted: 21 December 2016 / Published online: 29 December 2016

(C) The Author(s) 2016. This article is published with open access.

\begin{abstract}
Current climatic changes are occurring due to various human and industrial activities. In particular, the effects of urbanisation and growing threat of global warming have likely caused increasing precipitation in many geographic regions. For many years, portland cement pervious concrete (PCPC) has been making an important contribution, as a sustainable urban drainage system (SUDS), on improving environmental conditions. This type of porous concrete can help minimizing flooding risks, recharging ground water, reducing run off and peak flows, alleviating the precipitation load on overstressed drainage systems and improving water quality by capturing pollutants. The benefits of using PCPC in order to attenuate stormwater problems are quite essential mainly in urban areas where most surfaces typically consist of relatively impervious concrete or asphalt pavements, causing elevated levels of surface runoff. In addition, PCPC can reduce the absorption of solar radiation and urban heat storage potential which can lead to temperate urban conditions, and thus protecting the environment and health and safety of living things. However, PCPC requires regular maintenance to prevent any clogging of the pores by sediments and vegetation. This article provides an overview on pervious concrete mix design, key properties, durability and applications. Also, it touches on practical and scientific challenges of PCPC.
\end{abstract}

Keywords: Pervious concrete; Mechnical properties; Permeability; Durability

\section{Introduction}

With population growth, continual urbanisation has led to an increase of impervious surface areas, which block the percolation of precipitation from rainfall and snow down through the ground. This increases the potential for excess surface runoff, which can lead to downstream flooding, bank erosion and possibly transport of pollutants into potable water supplies. On the other hand, permeable pavements have the ability to reduce runoff volume and improve water quality. Indeed, they can store stormwater runoff until infiltrating into soil or conveyed downstream in the stormwater management system by a drain. For this reason, many communities are now exploring their use as an alternative low impact development design for stormwater control measures [1]. Such permeable pavement systems can contribute to solving drainage problems and reducing the risk of flash flooding, resulting from continuous urban developments.

Portland cement pervious concrete (PCPC) is a special type of concrete characterized by an interconnected pore structure and high void content/porosity typically in the range of 15 to $35 \%$ by volume. The use of PCPC may reduce flooding risk, recharge ground water, reduce stormwater runoff, reduce noise when in contact with vehicle tires, and prevent glare and skidding during rainy season by allowing water to infiltrate freely through its pores [2,3]. In addition, PCPC is produced at low cost, thus it can be considered among the most attractive sustainable urban drainage systems (SUDS). PCPC requires, however, regular maintenance to prevent any clogging of the pores by sediments and vegetation which might change its high permeability. PCPC can also undergo some durability issues related to abrasion and freeze-thaw cycles, which deter its wider application.

While its constituent materials are similar to that of normal concrete, PCPC contains little or no fine aggregate $[2,4]$. It is also known as no-fines concrete, permeable concrete, porous concrete and enhanced porosity concrete. PCPC has been used in a variety of applications, notable among which are low-traffic pavements such as parking lots and sidewalks, around buildings, and on highway shoulders and medians. Various PCPC mixes with different sizes and types of aggregate, binder contents, and admixtures have been investigated in the open literature. This article provides an overview on PCPC including its mix ingredients/proportions, key properties, durability and applications.

* Corresponding author: Mohammed Sonebi, E-Mail: m.sonebi@qub.ac.uk 


\section{Materials of PCPC}

PCPC uses the same materials as normal concrete. The porosity in PCPC is created by the elimination of fine aggregate and the use of coarse aggregate with a narrow or uniform grading to allow relatively low particle packing. The porosity and pores interconnectivity of PCPC are tailored given the application on hand and rainfall intensity. The pores size and interconnectivity are affected by the type, size and gradation of aggregate, paste volume, and consolidation energy [5]. The pore size in pervious concrete is also an important parameter as it affects properties such as permeability and sound absorption.

Aggregate grading generally used in PCPC are typically either single-sized coarse aggregate or grading between 9.5 and 19 $\mathrm{mm}$ [6]. PCPC made with single-sized aggregate has high permeability, but low strength development. Although aggregate with a maximum size of $37.5 \mathrm{~mm}$ has been successfully used, 20-mm maximum size is commonly used. Single-sized aggregate up to $25 \mathrm{~mm}$ also has been used [2]. The use of single-sized aggregates is essential to maintain the skeleton packing low enough to leave sufficient open pores in the matrix. In general, a relatively uniform large aggregate size is preferable for maximum infiltration rates $[5,6]$. Larger sized aggregate have produced larger pores and increased permeability. Although adding little sand amounts can improve the strength of PCPC when compared with single-sized mixes, the permeability is reduced. Indeed, a small amount of fine aggregate $(<2.4 \mathrm{~mm}$ ) has been found to be beneficial for strength and durability. It is also reported that the fine fraction of particles lower than D10 in the coarse aggregate can considerably influence the mechanical properties and hydraulic conductivity of pervious concrete [7]. When fine aggregate are used in PCPC, the paste volume should be adjusted to maintain the target void content.

Portland cement and supplementary cementitious materials (SCMs) are often used in PCPC. However, Kevern et al. [8] recommended that fly ash use be restricted to $10 \%$ and silica fume to $5 \%$ replacement to avoid very low early-age strength and rapid drying, respectively. Trial batches are strongly recommended to evaluate the important properties of PCPC given the application on hand, including consistency, setting time, strength development, porosity, and permeability. Densified silica fume was also used at $5 \%$ binder replacement to improve strength and bonding characteristics of PCPC [9]. Other additions to PCPC can include fibre reinforcement and waste/recycled materials which help promote sustainability and reduce the overall carbon footprint of PCPC.

Depending on the water-to-binder ratio $(w / b)$, either highrange or medium-range water reducing admixtures can be used in PCPC to facilitate handling and in-place casting to achieve target properties. Viscosity-modifying admixtures (VMAs) have been also used in PCPC to improve stability, reduce discharge time and enhance placement and consolidation [10]. Furthermore, VMAs can prevent paste to drain down and may increase both compressive and flexural strengths of PCPC [10]. On the other hand, air-entraining admixtures (AEA) are used in PCPC where freeze-thaw is a concern to reduce damage of PCPC. Because of the relatively low paste content and rapid setting time of PCPC, retarders are commonly used in PCPC.

\section{Mixture Design and Proportioning}

The design approach of PCPC is mainly based on proper selection of narrowly graded coarse aggregate and varying the paste volume until the target properties are achieved. The optimum water content that should be used in PCPC depends mainly on the gradation and physical characteristics of aggregate as well as the cementitious materials type and content. Typical $\mathrm{w} / \mathrm{b}$ ranging between 0.27 to 0.43 , sometimes combined with water reducing admixtures, is generally selected for desired workability [6]. The workability is assumed to be satisfactory when a handful sample of the mixture is squeezed and released resulting in a mixture that neither crumbles nor becomes void-free [6]. Typical ranges of mixture proportions reported in several studies are listed in Table 1.

A successful mix design for PCPC should consist of a balanced composition of materials to ensure the best performance in terms of permeability, strength, and durability. The most important condition in the design of PCPC is to keep the continuity of cement paste with coarse aggregate embedded so that continuous voids are maintained [11]. Generally, the aggregate-cement ratios $(\mathrm{A} / \mathrm{C})$ are in the range of 4 to 6 by mass. These $\mathrm{A} / \mathrm{C}$ ratios lead to aggregate contents between $1300 \mathrm{~kg} / \mathrm{m}^{3}$ to 1800 $\mathrm{kg} / \mathrm{m}^{3}$. Higher $\mathrm{A} / \mathrm{C}$ ratios have been used in laboratory studies, but with significant reduction in strength.

Figure 1 presents an example of PCPC cross-sectional area. It is a combination of good quality aggregate covered with adequate cementitious paste that leads to the formation of interconnected and disconnected pores. A balance between interconnected and disconnected pores will lead to PCPC with adequate permeability and reasonable strength.

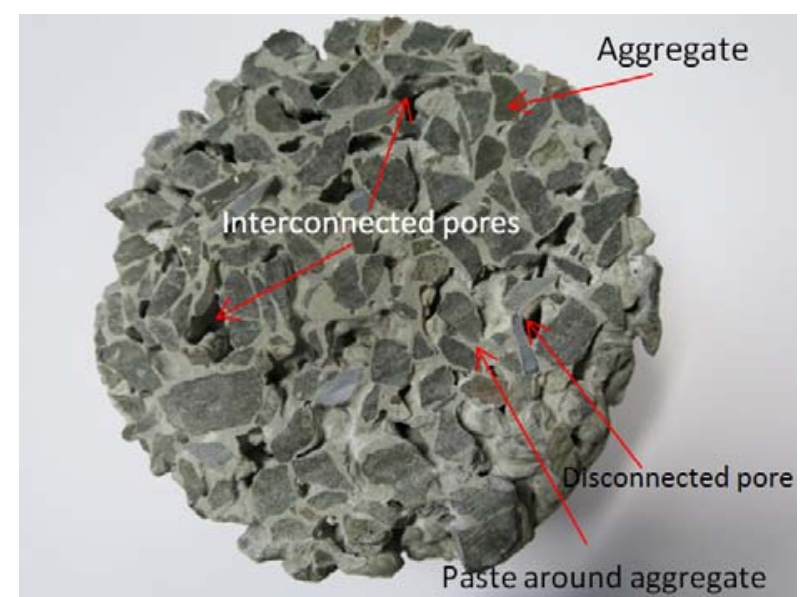

Figure 1. Cross-section of PCPC, illustrating porous structure. 


Table 1. Mixture proportions of PCPC
\begin{tabular}{|l|l|l|l|l|l|l|}
\hline References & Year & $\begin{array}{l}\text { Cementitious } \\
\text { material(CM) }\end{array}$ & Aggregates (kg/m $\left.{ }^{3}\right)$ & W/CM & Agg./CM ratio & Water (W) \\
\hline Khankhaje et al. [12] & 2016 & 340 & 1460 & 0.32 & -- & 109 \\
\hline Chandrappa et al. [13] & 2016 & $321-487$ & $1373-1692$ & $0.25-0.35$ & $3.0-5.0$ \\
\hline Yahia \& Kabagire [7] & 2014 & $195-535$ & $1500-1700$ & 0.30 & -- & $84-161$ \\
\hline Nguyen et al. [14] & 2013 & 309 & 1525 & 0.30 & 4.9 & -- \\
\hline Bassuoni \& Sonebi [15] & 2010 & $315-415$ & $1200-1400$ & $0.28-0.40$ & $4-6$ \\
\hline Kervern et al., [16] & 2009 & $180-380$ & $1510-1820$ & $0.24-0.30$ & $4.0-10$ \\
\hline Crouch et al. [17] & 2007 & $287-345$ & $1542-1620$ & 0.30 & $4.5-5.6$ \\
\hline Ghaffori et al. [18] & 1995 & $300-413$ & $1651-1800$ & $0.37-0.42$ & $4-6$ \\
\hline
\end{tabular}

\section{$4 \quad$ Key Properties of PCPC}

PCPC has stiff consistency as indicated by zero slump, and thus it needs considerable compaction effort to achieve the desired mechanical performance, without neglecting permeability properties which are strongly dependent on its open porosity (volume of voids). The strength of hardened PCPC is created by the bonding between the cementitious paste and aggregate. There are many factors affecting the strength of PCPC including the cementitious content, w/b, compaction level and aggregate gradation and quality. For the optimisation of any PCPC mix design, a balance between the strength and permeability is the key factor. It is generally accepted that the compressive strength of PCPC is related to strength of paste and aggregate and void ratio [2]. It can also be noted that the compaction effort/technique will affect the void content. The density of PCPC ranges from 1600 to $2000 \mathrm{~kg} / \mathrm{m}^{3}[19,20]$, which is relatively lower than that of normal concrete due to the significantly higher volume of voids (15 to $35 \%$ ). A typical relationship between the void ratio and fresh density of PCPC is shown in Fig. 2 [15].

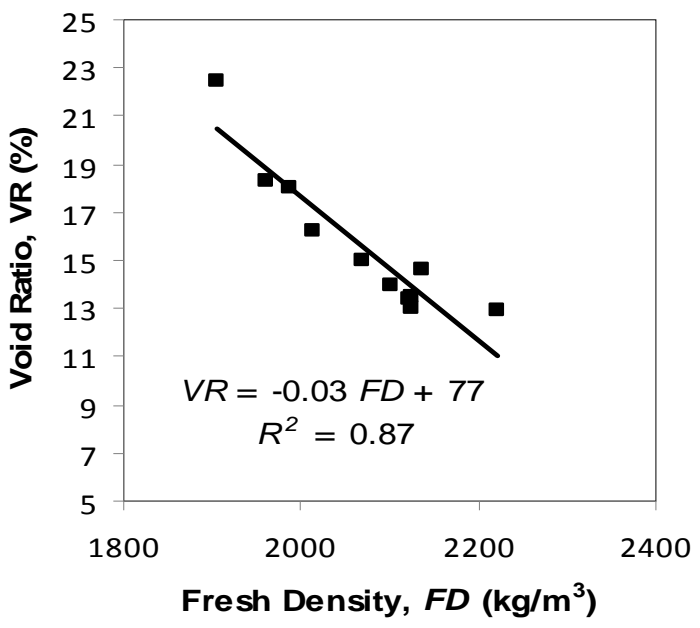

Figure 2. Relationship between void ratio and fresh density of PCPC [15].

Previous studies have chosen different procedures to reproduce in-situ compaction in order to achieve consistent results for laboratory specimens. The compaction methods included tamping, vibration, and use of a proctor hammer [21], but to-date there is no standard for this procedure. PCPC mixes can develop compressive strength in the range of 5 to $30 \mathrm{MPa}$, with typical values of about $17 \mathrm{MPa}$, which is suitable for a wide range of applications, such as light traffic pavements $[2,4,14]$. Correspondingly, the flexural strength of PCPC can range between 1 to $3.5 \mathrm{MPa}[4,19]$. Crouch et al. [22] reported that the relationship between the compressive $\left(f_{c}^{\prime}\right)$ and flexural $\left(f_{r}\right)$ strength of PCPC can be represented by Eq. 1 , and the splitting tensile strength is typically $65 \%$ of the flexural strength of PCPC.

$$
f_{r}=0.083 f_{c}^{\prime 2 / 3} \text { (SI units) }
$$

At constant cement content, increasing the $\mathrm{w} / \mathrm{b}$ from 0.28 to 0.40 in PCPC mixes increases compressive strength, as this produces a higher volume of paste in excess of the amount needed to encapsulate the aggregate for bonding the PCPC matrix. Surplus paste clogs the open pore structure of PCPC, thus reducing the void ratio and increasing compressive strength [20]. Conversely, a very low $\mathrm{w} / \mathrm{b}$ can lead to reduced adhesion between aggregate particles and placement problems. Similar to normal concrete, the addition of SCMs can enhance the hardened properties of PCPC. For example, the pozzolanic reaction induced by silica fume can enhance the compressive strength of PCPC. The compressive strength of PCPC can also be improved if the cementitious binder area is increased. Smaller aggregate can be used to increase the aggregate particle per unit volume, thus increasing the cementitious paste binding area [7]

Research on polymer modified PCPC highlights that with the use of polymer additives, the compressive and splitting tensile strengths of PCPC can be enhanced [23]. Polymer emulsions may fill more voids, thus increasing the strength of PCPC, but the permeability is concurrently decreased. Fibre reinforcement can also be used to increase the tensile strength of PCPC. Careful selection of the best fibre reinforcement will depend on its interaction with a given PCPC mix. Metallic reinforcement would not be suitable for PCPC, as the open pore structure provides conditions favourable to corrosion. Fibres made of glass, carbon, synthetic or natural materials (seashell, oil palm kernel shell, palm oil clinker) may be used to enhance the performance of PCPC $[12,14,24-28]$. Hence, the strength of PCPC can be relatively increased by compromising permeability and improving the properties of the paste and interface/bond between the paste and aggregate. Below are some strategies that can be used to increase the strength of PCPC:

\section{- $\quad$ increasing compaction effort;}

- $\quad$ incorporating a small amount of fine aggregate into the mix to fill up some portion of the pores; 
- $\quad$ adding polymers and non-metallic fibres;

- using small aggregate sizes, depending on paste/aggregate, to increase the contact area of the aggregate particles with the paste; and

- incorporating supplementary cementitious materials, such as silica fume and fly ash in the binder.

High porosity and permeability (Fig. 3) properties are the main characteristics pertinent to PCPC as it has a very high void ratio in the range of about $15-35 \%$. The variation of permeability of PCPC can range between 81 to 730 $\mathrm{L} / \mathrm{min} / \mathrm{m}^{2}$, with a typical rate of $120-320 \mathrm{~L} / \mathrm{min} / \mathrm{m}^{2}$, depending on compaction, void content, materials and subbase infiltration rates [6]. Similar to strength, the void ratio is directly linked to the infiltration/permeability of PCPC. The porous void network is achieved through the different compaction techniques used to produce this material. Previous research shows that an optimum void content of $15-25 \%$ produces adequate strength and infiltration, e.g. $[11,20]$.

The American Society for Testing and Materials (ASTM) C1701/M [29] test method is used for testing infiltration of in-situ pervious concrete based on the principal of a fallinghead permeability method to calculate the coefficient of permeability $(k)$ using the principles of Darcy's law. A typical relationship between the void ratio and permeability of PCPC is shown in Fig. 4 [15]. The figure shows a good association between these two properties with a coefficient of determination $\left(R^{2}\right)$ of 0.82 . The non-linear behaviour is attributed to the dependence of the infiltration rate on the percentage of voids as well as their interconnectivity. The permeability of PCPC is also dependent upon pore-size distribution, pore roughness, and partitioning of the pore space [30]. Since a good correlation also exists between the fresh density and void ratio of PCPC (Fig. 2), it may be suggested that the fresh density test can act as a viable quality control/performance measure for the acceptance of PCPC, which can be determined by ASTM C1688 [31].

\section{Durability of PCPC}

Previous research recommends that PCPC has the ability to reach a service life of up to 20 years depending on its application. Poor design, poor construction, and poor area preparation can lead to design malfunctions [32]. Cracking, rutting, clogging of pores, sub soils with poor infiltration and inadequate maintenance can all contribute to the failure of PCPC working effectively. Resistance of PCPC to freezingthawing $(F / T)$ cycles and abrasion are challenging durability issues.

Experimental studies have revealed that PCPC has been successfully applied in harsh winter regions, such as Indiana, Illinois, and Pennsylvania [33-37]. The voids in PCPC can provide $F / T$ resistance if these voids sufficiently drain precipitation before freezing. Air-entrainment of paste can also improve $\mathrm{F} / \mathrm{T}$ resistance of $\mathrm{PCPC}$ in a similar manner to normal concrete [2].

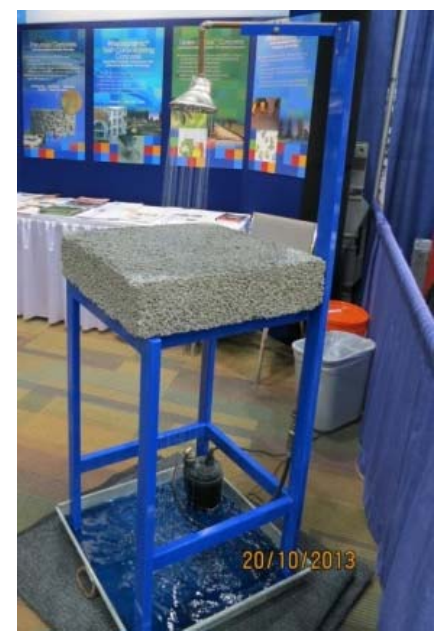

Figure 3. Water infiltration in PCPC.

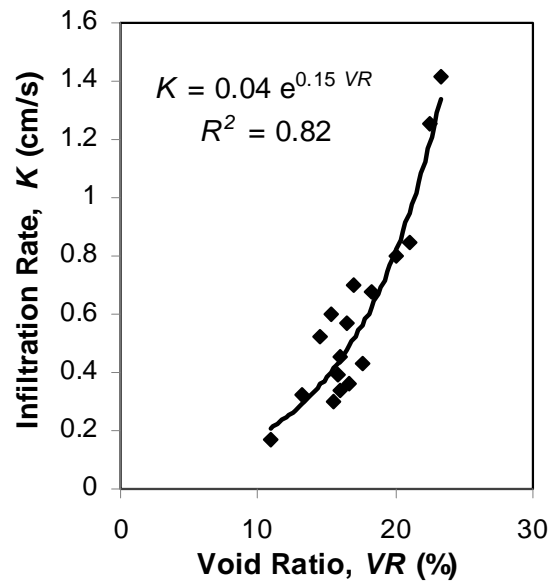

Figure 4. Relationship between void ratio and infiltration rate of PCPC [15].

The performance of PCPC under F/T conditions is affected by the number of cycles and their frequency. It has been shown that PCPC subjected to $80 \mathrm{~F} / \mathrm{T}$ cycles applied at a rapid rate $(5 \mathrm{cycles} /$ per day) retained a relative dynamic modulus of less than $40 \%$, whereas the same mix design tested with $1 \mathrm{~F} / \mathrm{T}$ cycle/day retained a value greater than $90 \%$ [38].

By altering the mix design of PCPC for example by introducing sand, latex and even air-entrainment, the resistance of $P C P C$ to $F / T$ cycles will improve due to preventing debonding between the aggregates and cement paste. Furthermore, compaction can influence the resistance of PCPC to $F / T$ cycles. Higher compaction energy will obviously make the matrix less porous, and thus improving its resistance to F/T cycles. In addition, proper maintenance of PCPC will likely reduce its failure due to frost action by allowing water to pass through it freely without being trapped inside the pore structure. This maintenance process can be done annually by either spraying or using vacuum to remove debris that can clog the pore structure of PCPC [39].

Some experimental studies have indicated that PCPC has poor $\mathrm{F} / \mathrm{T}$ resistance when tested under fully saturated conditions [37]. However, this is a significantly severe 
method used to test conventional concrete and is not representative of the potential field exposure conditions of properly designed and constructed pervious concrete pavements. It is possible to add air-entraining admixtures to PCPC mixtures to protect the paste, but the entrainment of air cannot be verified or quantified by normal standard test methods. Gesoglu et al. [40] reported that the replacement of natural aggregates by tire chips-crumb rubber at $10 \%$ and $20 \%$ by equivalent volume remarkably improved frost resistance of $\mathrm{PCPC}$.

It was reported that there were strong relationships between strength and F/T resistance of PCPC, which indicates that PCPC mixes with relatively higher strength may achieve better durability [41]. In addition, polypropylene fibers with various lengths $(3-12 \mathrm{~mm})$ showed observable reinforcement effect on the freeze-thaw resistance and a proper content of air entraining admixture could increase the compactability and uniformity of the PCPC mixture, and thus improving its $F / T$ resistance to some extent.

The F/T resistance of PCPC can be assessed by ultrasonic pulse velocity and dilation of specimens. However, the preferred assessment parameters of PCPC breakdown are mass loss and visual inspection. The breakdown of PCPC due to frost action can be improved with $[23,37,42]$ :

- use of air-entrainment additives which allow tiny air bubbles to stabilise within the cementitious paste;

- use of small proportions of fine aggregates to increase strength;

- $\quad$ use of latex additives and fibres to improve bonding and tensile strengths;

- $\quad$ proper sub-base preparation, i.e. increased drainage;

- frequent maintenance to prevent entrapment of water within the pore structure; and

- $\quad$ use of French drains to increase soil permeability.

Abrasion and impact can be measured to estimate the surface wear resistance of PCPC according to ASTM C1747 [43]. Other researchers investigated the abrasion resistance of PCPC using rotating-cutter [44]. The Cantabro test, the loaded wheel abrasion test, and the surface abrasion tests were used by Dong et al. [45] to assess the abrasion resistance of PCPC. It was reported that all tests were effective to compare the results of PCPC made with different aggregates. However, the Cantabro test seems to reflect more impact rather than abrasion. Wu et al. [46] reported the abrasion resistance, tested with the Cantabro and Asphalt Pavement Analyzer (APA) abrasion tests, of PCPC made with smaller aggregates was better than that of $a$ corresponding mix made with larger aggregates. The addition of latex improved slightly the abrasion resistance of PCPC; however, the use of polypropylene fibres did not show any significant effect on abrasion. The nature of aggregate affects significantly the abrasion resistance of PCPC similar to conventional concrete [47]. Rangelov et al. [26] studied the effect of different size of fractions of cured carbon fibre composite (CCFC) on abrasion resistance. They observed that these mixtures containing CCFC performed better than the control mixture using both the Cantabro and surface abrasion tests [26]. The abrasion resistance of PCPC made with recycled concrete block aggregates (RBA) and recycled concrete aggregates (RCA) was investigated by Zaetang et al. [48]. It was observed that the incorporation of RCA at different percentages ( 20 to $100 \%$ by weight) led to an improvement of abrasion resistance and with up $20 \%$ replacement of RBA. This enhancement was due to better bonding between RCA and cement paste which had high surface porosity and roughness [48].

\section{Applications of PCPC}

PCPC is normally used without any reinforcement due to high risk of corrosion because of the open pores in its structure. Some applications of PCPC include pervious pavement for parking lots, rigid drainage layers under exterior areas, greenhouse floors to keep the floor free of standing water, structural wall applications where lightweight or better thermal insulation characteristics, or both are required, elements where better acoustic absorption characteristics are desired, base course for roads, surface course for parking lots, tennis courts, zoo areas, animal barns, swimming pool decks, beach structures, seawalls, embankments, etc. $[2,37,49,50]$.

PCPC is typically used as a pavement in light-traffic areas and parking lots. The placement of PCPC is very important and specialised procedures are applied to ensure achieving target performance. It must have a combined system in so far as it has to conform to the sub-base and the underlying soil (Fig. 5). Indeed, the soil has to have sufficient bearing capacity to support the intended loading for the proposed application of PCPC. Fig. 5 presents a general cross-section of PCPC pavement, which is typically placed on top of clean drainage stone. A layer of non-woven geo-textile is placed below the clean drainage stone to act as a filtration media, before infiltration of precipitation to soil.

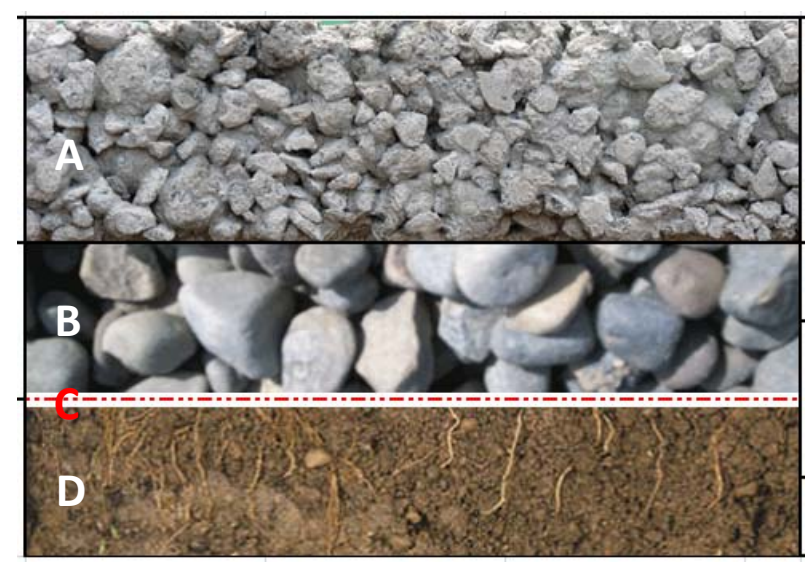

Figure 5. A typical pervious concrete pavement section: $A$ - pervious concrete, B - clean drainage stone, C - nonwoven geotextile, D underlying soil.

PCPC is compacted on site through a combination of weighted rollers and surface vibrators. Joints are needed in 
all concrete pavements as atmospheric conditions and surface loading can cause material beds to move slightly. Joints are created by a roller with a blade. Jointing of PCPC is crucial for long term durability factors. PCPC can also be affected by shrinkage and lateral movement. It is therefore common that joints are spaced at 6 meter intervals [66]. Due to the nature of compaction, PCPC generally has higher strength, lower void ratio, and therefore a lower permeability at the surface than at the bottom [51]. Curing of PCPC occurs within 20 minutes of its placements. It is important that the curing of PCPC is kept controlled as excess evaporation of moisture will inhibit the hydration of cementitious materials, thus deterring strength development [2-4]. Thus, hydration stabilizers may be added to mitigate this effect.

\section{Recommended Scope for Future Research}

While there have been numerous studies on PCPC, there is still dearth of information in some areas. Some mix design proportions and ranges of PCPC have been gathered in this article, but so far there is no universal/standardized mix design method. Regarding its durability performance, there is a concern about the $F / T$ and de-icing salt resistance of PCPC, which deter its wider application in colder climates. Nevertheless, there have been a number of PCPC pavement projects in wet and freezing environments, demonstrating good field performance over several years. Thus, more research is needed to address this issue, especially regarding the appropriate test methods that should be used to evaluate the frost and salt-frost resistance of PCPC. For the clogging aspect, there is need to do more research in order to gain knowledge of the surrounding soils necessary for designing an efficient PCPC pavement system. This knowledge can be used to mitigate excessive depositions of sediments such as silts and clays. In addition, there is need for more studies focusing on correlating results obtained from laboratory to field data with respect to the compaction, porosity, permeability, curing, quality of joints, and durability of PCPC. To date, there is also lack of advanced structural behaviour and modelling of PCPC pavements, repair and rehabilitation techniques specifically applicable to PCPC, thermal behaviour in the field, fatigue and life cycle analysis of PCPC over a long period of time. Indeed, research in these directions will help promoting the wider use of PCPC in different applications.

\section{References}

[1] P.T. Weiss, M. Kayhanian, L. Khazanovich, J.S. Gulliver, Permeable Pavements in Cold Climates: State of the Art and Cold Climate Case Studies, Final Report Published by Minnesota Department of Transportation Research Services \& Library, June 2015.

[2] P.D., Tennis, M.L. Leming, DJ. Akers, Pervious Concrete Pavements, EB302.02, Portland Cement Association, Skokie, IL, and National Ready Mixed Concrete Association, Silver Spring, MD, USA, 2004.

[3] M. Scholz, P. Grabowwiecki, Review of permeable pavement systems, Build Env (2007) 42(11): 2972-2979. https://doi.org/10.1016/i.buildenv.2006.11.016
[4] K. Obla, Pervious Concrete for Sustainable Development, Proceedings of the First International Conference on Recent Advances in Concrete Technology, Sep. 2007, Washington DC, USA.

[5] I. Andrew, J.P. Bradley, Effect of aggregate size and gradation on pervious concrete mixtures. ACI Mater J (2010) 107(6): 625-631.

[6] ACl 522R-10, Report on Pervious Concrete, American Concrete Institute, Farmington Hills, MI, USA, 2010 (Reapproved 2011).

[7] A. Yahia, D. Kabagire, New approach to proportion pervious concrete, Constr Build Mater (2014) 62: 38-46. https://doi.org/10.1016/j.conbuildmat.2014.03.025

[8] J.T. Kevern, V.R. Schaefer, K. Wang, M.T. Suleiman, Pervious concrete mixture proportions for improved freeze-thaw durability. J ASTM Inter (2008) 5(2).

[9] V.R. Schaefer, K. Wang, M.T. Sulieman, JT. Kevern, Mix design development for pervious concrete in cold weather climates, Final Report, National Concrete Pavement Technology Center, lowa State University, Ames, IA, USA, 2006.

[10] K. Hannele, N. Emma, L. Kalle, Pervious pavement systems and materials, State of the Art. Research Report of the Technical Research Centre of Finaland. 2013.

[11] P. Chindaprasrit, S. Hatanaka, T. Chareerat, N. Mishima, Y. Yuasa, Cement paste characteristics and porous concrete properties, Constr Build Mater (2008) 22: 894-901. https://doi.org/10.1016/j.conbuildmat.2006.12.007

[12] E. Khankhaje, M.R. Salim, J. Mirza, M.W. Hussin, M. Rafieizonooz, Properties of sustainable lightweight pervious concrete containing oil palm kernel shell as coarse aggregate, Constr Build Mater (2016) 126: 1054-1065. https://doi.org/10.1016/j.conbuildmat.2016.09.010

[13] A.K. Chandrappa, K.P. Biligori, Comprehensive investigation of permeability characteristics of pervious concrete: A hydrodynamic approach, Constr Build Mater (2016) 123: 627-637. https://doi.org/10.1016/j.conbuildmat.2016.07.035

[14] D.H. Nguyen, M. Boutouil, N. Sebaibi, L. Leleyter, F. Baraud, Valorization of seashell by-products in pervious concrete pavers, Constr Build Mater (2013) 46: 151-160. https://doi.org/10.1016/j.conbuildmat.2013.08.017

[15] M.T. Bassuoni, M. Sonebi, Pervious concrete: a sustainable drainage solution, Concr, The Concr Soc (2010) 44: 14-16.

[16] J.T. Kevern, V.R. Schaefer, K. Wang, Evaluation of pervious concrete workability using gyratory compaction, J Mater Civil Eng, (2009) 21: 764-770. https://doi.org/10.1061/(ASCE)0899-1561(2009)21:12(764)

[17] L.K. Crouch, J. Pitt, R. Hewitt, Aggregate effects on pervious portland cement concrete static modulus of elasticity, J Mater Civ Eng (2007) 19: 561-568. https://doi.org/10.1061/(ASCE)0899-1561(2007)19:7(561)

[18] N. Ghafoori, S. Dutta, Laboratory investigation of compacted nofines concrete for paving materials, J Mater Civ Eng (1995), 7 (3): 183-191. https://doi.org/10.1061/(ASCE)0899-1561(1995)7:3(183)

[19] R.C. Meininger, No-fines pervious concrete for paving, Concr Int (1988) 10: 20-27.

[20] M. Sonebi, M.T. Bassuoni, Investigating the effect of mixture design parameters on pervious concrete by statistical modelling, Constr Build Mater (2013) 38: 147-154. https://doi.org/10.1016/j.conbuildmat.2012.07.044

[21] K.C. Mahboub, J. Canler, R. Rathbone, T. Robl, B. Davis, Pervious concrete: compaction and aggregate gradation, ACI Mater J (2009) 106: 523-528.

[22] L.K. Crouch, N. Smith, A.C. Walker, T.R. Dunn, A. Sparkman, Determining Pervious PCC Permeability with A Simple Triaxial Flexible-Wall Constant Head Permeameter, TRB 85th Annual Meeting Compendium of Papers, 2006.

[23] M. A. Pindado, A. Aguado, A. Josa, Fatigue Behavior of PolymerModified Porous Concretes, Cem Concr Res (1999) 29: 1077-1083. https://doi.org/10.1016/S0008-8846(99)00095-2

[24] B. Rehder, K. Banh, N. Neithalath, Fracture behavior of pervious concretes: the effects of pore structure and fibers, Eng Fract Mech (2014) 118: 1-16. https://doi.org/10.1016/j.engfracmech.2014.01.015

[25] J.T. Kevern, D. Biddle, Q. Cao, Effects of macrosynthetic fibres on pervious concrete properties, J Mater Civ Eng (2014) 6: 15-21. http://dx.doi.org/10.1061/(ASCE)MT.1943-5533.0001213

[26] M. Rangelov, S. Nassiri, L. Haselbach, K. Englund, Using carbon fiber composites for reinforcing pervious concrete, Constr Build Mater (2016) 126:875-885 https://doi.org/10.1016/i.conbuildmat.2016.06.035 
[27] K. Ćosić, L. Korat, V. Ducman, I. Netinger, Influence of aggregate type and size on properties of pervious concrete, Constr Build Mater (2015) 78:69-79. https://doi.org/10.1016/j.conbuildmat.2014.12.073

[28] H.A. Ibrahim, H.A. Razak, Effect of palm oil clinker incorporation on properties of pervious concrete, Constr Build Mater (2016) 115: 7077. https://doi.org/10.1016/j.conbuildmat.2016.03.181

[29] ASTM C1701/C1701M-09, Standard Test Method for Infiltration Rate of In Place Pervious Concrete, American Society for Testing and Materials, West Conshohocken, PA, USA, 2009.

[30] N. Neithalath, J. Weiss, J. Olek, Characterizing Enhanced Porosity Concrete using electrical impedance to predict acoustic and hydraulic performance, Cem Concr Res (2006) 36:2074-2085. http://dx.doi.org/10.1016/j.cemconres.2006.09.001

[31] ASTM C1688/C1688M-14, Standard Test Method for Density and Void Content of Freshly Mixed Pervious Concrete, American Society for Testing and Materials, West Conshohocken, PA, USA, 2014.

[32] EPA, Environment Protection Agency, Storm Water Phase II Final Rule: An Overview, EPA 833-F-00-001, Fact Sheet 1.0, US Environmental, Protection Agency, Office of Water, January 2000.

[33] V.R. Schaefer, J.T. Kerven, Installation and maintenance considerations for improved freeze-thaw durability of pervious concrete, J Mater Civ Eng (2013) 25:459-470. https://doi.org/10.1061/9780784412978.045

[34] J.T. Kerven, V.R. Schaeder, K. Wang, M.T. Sulieman, Pervious concrete mix proportions for improved freeze-thaw durability, J Test Eval (2009) 37(4): 337-342.

[35] J.T. Kerven, V.R. Schaefer, Mixture proportioning considerations for improved freeze-thaw durability of pervious concrete, J Mater Civ Eng (2013) 25:886-892. http://dx.doi.org/10.1061/9780784412978.046

[36] I. Anderson, M.M. Dewoolkar, Laboratory Freezing-and-Thawing Durability of Fly Ash Pervious Concrete in a Simulated Field Environment, ACI Mater J (2015) 112(5): 603-612. https://doi.org/10.14359/51687921

[37] M.S. Lund, J.T. Kevern, V.R. Schaefer, K.K. Hansen, Mix design for improved strength and freeze-thaw durability of pervious concrete fill in Pearl-Chain Bridges, Mater Struct (2017) 50: 42. http://dx.doi.org/10.1617/s11527-016-0907-4

[38] [38] J. Olek, WJ. Weiss, Development of Quiet and Durable Porous Portland Cement Concrete Paving Materials. Final Report SQDH 2003-5 Center for Advanced Cement Based Materials, Purdue University, West Lafayette, IN, 2003.

[39] M. Zaldo, Pervious concrete pavements industry focus, National Ready Mixed Concrete Association, 2006.

[40] M. Gesoglu, E. Guneyisi, G. Khoshnaw, S. Ipek, Abrasion and freezing-thawing resistance of pervious concretes containing waste rubbers, Constr Build Mater (2014) 73:19-24. https://doi.org/10.1016/j.conbuildmat.2014.09.047

[41] H. Wu, Z., Liu, B. Sun, J. Yin, Experimental investigation on freezethaw durability of Portland cement pervious concrete (PCPC), Constr Build Mater (2016) 117: 63-71. https://doi.org/10.1016/j.conbuildmat.2016.04.130

[42] V.R. Schaefer, K. Wang, M.T. Sulieman, J.T. Kevern, Mix Design Development for Pervious Concrete in Cold Weather Climates, Final Report, National Concrete Pavement Technology Center, lowa State University, Ames, IA, USA, 2006.

[43] ASTM C1747/C1747M-13, Standard test method for determining potential resistance to degradation of pervious concrete by impact and abrasion, American Society for Testing and Materials, West Conshohocken, PA, 2013.

[44] J.T. Kerven, V.R. Schaeder, K. Wang, The effect of curing regime on pervious concrete abrasion resistance, J ASTM Int (2008) 5(2): 12.

[45] Q. Dong, H. Wu, B. Huang, X. Shu, K. Wang, Investigation into laboratory abrasion test methods for pervious concrete, J Mater Civ Eng (2013) 25:886-892. https://doi.org/10.1061/(ASCE)MT.1943-5533.0000683

[46] H. Wu, B. Huang, X. Shu, Q. Dong, Laboratory evaluation of abrasion resistance of Portland cement pervious concrete (PCPC), J Mat Civil Eng (2011) 23: 697-702. https://doi.org/10.1061/(ASCE)MT.1943-5533.0000210

[47] C. Gaedicke, A. Marines, F. Miankodila, Assessing the abrasion resistance of cores in virgin and recycled aggregate pervious concrete, Constr Build Mater (2014) 68: 701-708. https://doi.org/10.1016/i.conbuildmat.2014.07.001

[48] Y. Zaetang, V. Sata, A. Wongsa, P. Chindaprasirt, Properties of pervious concrete containing recycled concrete block aggregate and recycled concrete aggregate, Constr Build Mater (2016) 111: 875885. https://doi.org/10.1016/j.conbuildmat.2016.02.060

[49] D. Huffman, Understanding pervious concrete, Constr Spec (2005) 12: 43-49.

[50] J. Mullaney, T. Lucke, Practical Review of Pervious Pavement Designs, Clean Soil Air Water J (2014) 42: 111-124.

[51] N. Delatte, A. Mrkajic, D. Miller. Field and Laboratory Evaluation of Pervious Concrete Pavements. Trans Res Rec (2009) 2113: 132-139. https://doi.org/10.3141/2113-16 